\section{TÀI LIÊU THAM KHẢO}

1. Ngố Quý Châu (2018), Bệnh Học Nội Khoa Tập 2, Nhà xuất bản Y họ , 232-242

2. Phùng Đức Tâm ( 2019), Biến chứng nhiễm khuẩn do tiêm khớp và tiêm phần mềm cạnh khớp tại tuyến dưới được chẩn đoan và điều trị tại khoa Cơ Xương Khớp bệnh viện Bạch Mai, Tạp Chí Học Viêt Nam Tháng 5. 2019;478(Số đăc biết), 191-197.

3. Mathews $\mathrm{CJ}$, Weston VC, Jones A, Field M, Coakley G (2010), Bacterial septic arthritis in adults, The Lancet, 375(9717), 846-855. doi:10.1016/S0140-6736(09)61595-6

4. Newman JH (1976), Review of septic arthritis throughout the antibiotic era, Ann Rheum Dis,
35(3), 198-205. doi:10.1136/ard.35.3.198

5. McBride S, Mowbray J, Caughey W, et al. Epidemiology (2020). Management, and Outcomes of Large and Small Native Joint Septic Arthritis in Adults, Clin Infect Dis;70(2), 271-279. doi:10.1093/cid/ciz265

6. Favero $M$, Schiavon $F$, Riato $L$, Carraro $V_{\text {, }}$ Punzi L (2008), Rheumatoid arthritis is the major risk factor for septic arthritis in rheumatological settings, Autoimmun Rev,2008;8(1), 59-61. doi:10.1016/j. autrev.2008.07.018

7. Eun Jin Kim, Kyoung Hwa Ha, Dae Jung Kim, Young Hwa Choi (2019), Diabetes and the Risk of Infection, A National Cohort Study, Diabetes Metab J, 43(6). doi:10.4093/dmj.2019.0071

\title{
KẾT QUẢ SỚM PHẪU THUÂTT CẮT BÁN PHẦN CỰC DƯớI VÀ PHỤC HỒI LƯU THÔNG DÁ DÀY - RUộT THEO ROUX EN Y TRONG UNG THƯ HANG MÔN VII DẠ DÀY
}

\section{TÓM TẮT}

Mục tiêu nghiên cứu: Đánh giá kết quả sớm phẫu thuật cắt bán phần cực dưới và phục hồi lưu thông da dày - ruột theo Roux en $Y$ trong ung thư hang mổn vị dạ dày tại bệnh viện K từ 6/2019 đến 6/2021. Đối tượng và phương pháp nghiên cứu: Nghiên cứu mô tả trên 55 bệnh nhân chân đoán ung thư hang môn vị tại bệnh viện $K$ từ 6/2019 đến 6/2021 được phẫu thuâat cắt bán phân cực dưới và phục hồi lưu thông dạ dày - ruột theo Roux en Y. Kết quả: Thời gian nằm viện trung bình là $8,65 \pm 2,30$ ngày, trong đó thời gian nằm viện của nhóm phấu thuật nội soi (trung bình 7,36 $\pm 1,21$ ngày) ngắn hơn nhóm mổ mở (trung bình $8,98 \pm 2,41$ ngày), với sự khác biệt có ý nghĩa thống kê $(p=0.004)$. Tỷ lệ biến chứng sớm sau mổ $5,45 \%$ (đều là nhiếm trùng vết mổ). Tại thời điểm 6 tháng sau mổ, tỷ lệ viêm miênng nối là $25,45 \%$, tỷ lệ trào ngược là $12,73 \%$, hội chứng Dumping gặp $3,64 \%$, không có trường hớp nào mắc hội chứng Roux. Tỷ lệ bệnh nhân tăng cẩn trở lại là $83,64 \%$, chất lượng cuộc sống theo thang điểm Spitzer đạt từ 8 điểm trở lên là $90.91 \%$. Kết luận: Phuc hồi lưu thông da dày - ruột theo Roux en Y sau phẩu thuật cắt bán phân cực dưới dạ dày mang lại nhiều lợi î́ch sau mố với tỷ lệ biến chứng sớm, biến chứng tại thời điểm 6 tháng sau mổ thấp và chất lượng cuộc sống tốt cho bệnh nhân.

Tư khoá: Ung thư dạ dày, cắt bán phân cực dưới dạ dày, Roux en Y.

\footnotetext{
*Trường Đại học Y Hà Nội

Chịu trách nhiệm chính: Nguyễn Thanh Thông

Email: Thongnthmu@gmail.com

Ngày nhận bài: 21.6.2021

Ngày phản biện khoa học: 18.8.2021

Ngày duyệt bài: 24.8.2021
}

Nguyễn Thanh Thông*, Kim Văn Vụ*

\section{SUMMARY \\ EARLY RESULT OF DISTAL SUBTOTAL GASTRECTOMY AND ROUX EN Y RECONSTRUCTION FOR PYLORICCANCER OF GASTRIC ANTRUM}

Objective: To evaluate theearly results of patients who underwent distal subtotal gastrectomy and Roux en $\mathrm{Y}$ reconstruction for cancer of gastric antrum. Patients and methods: Description study of 55 patientsunderwent distal subtotal gastrectomy and Roux en $Y$ reconstruction for cancer of gastric antrum in Vietnam's National Cancer Hospital from 6/2019 to 6/2021. Results: Median length of hospital stay was8,65 $\pm 2,30$ days, with statistically significant shorter in the laparoscopic surgery group (average) is shorter thanopen surgery group $(7,36 \pm 1,21$ days vs $8,98 \pm 2,41$ days; $p=0,004)$. Three patients $(5.45 \%)$ experienced early complications, of are wound infections). About late complications at 6 months after surgery, the incidence of remnant gastritis was $25,45 \%$, reflux symptoms was $12,73 \%$, dumping syndrome was $3,64 \%$ and there are no cases of Roux syndrome. Fourty-six patients (83.64\%)gained weight. $90,91 \%$ of patients scored 8 or higher on a 10 -point forthe Spitzer Quality of life Index. Conclusions: Roux en $Y$ reconstruction after distal subtotal gastrectomy has bringed benefits to patients with low rate of early complications or late complications at 6 months after surgery and good quality of life.

Keywords: Gastric cancer, distal subtotal gastrectomy, Roux en Y.

\section{I. ĐĂT VẤN ĐỀ}

Ung thư da dày là môt trong các loai ung thư phổ biến trên thế giới cũng như ở Việt Nam và đứng hàng đâuu trong ung thư đường tiêu hóa. Theo Globocan 2020, tại Việt Nam, ung thư dạ 
dày là nguyên nhân gây tử vong thứ $3(11,9 \%)$ sau ung thư gan,phổi và đứng thứ $4(9,8 \%)$ trong số các trường hợp mới mắc, sau ung thư gan, phổi, vúi ${ }^{1}$. Vị trí hay gặp nhất của ung thư da dày là $1 / 3$ dưới, tức vùng hang môn vị. Tỷ lệ này ở Mỹ là $45 \%$ và ở Việt Nam theo nhiêu thống kê có hơn $80 \%{ }^{2}$. Cho tới nay, điêu trị ung thư dạ dày bằng phẫu thuật vẫn là lựa chọn hàng đầu khi khối u vẫn còn khả năng cắt bỏ. Các phương pháp khác như hốa chất, miễn dịch, xạ trị chỉ được coi là điều trị hỗ trợ tùy thuộc vào tình trạng bênh nhân và giai đoạn bệnh.

Phục hồi lưu thông tiêu hoá dạ dày-ruột sau phẫu thuật cắt bán phân dạ dày được thực hện bằng nhiều phương pháp khác nhau như Billroth I, Billroth II (Polya hoăc Finsterer), hoăc Roux en Y. Trong khi Billroth I là phương pháp đơn giản và phù hợp sinh lý, thì Billroth II và Roux en Y là sự lựa chọn thay thế khi Billroth I không được chỉ định. Tuy nhiên trong những năm gần đây, đã có nhiều nghiên cứu trên thế giới cho thấy sự ảnh hưởng các phương pháp phục hồi lưu thông dạ dày - ruột sau phẫu thuật cắt bán phân cực dưới trong ung thư hang môn vị đến chất lượng cuộc sống của bệnh nhân. Tại bệnh viện K Trung ương cũng như Việt Nam, các nghiên cứu đánh giá kết quả của phương pháp phục hồi lưu thông da dày-ruôt theo kiểu Roux en Y sau phẫu thuât cắt bán phân cực dưới da dày chưa được công bố nhiêu.

Trên cơ sở lý luận và thực tiễn đó, chúng tôi tiến hành nghiên cứu này với mục tiêu: "Đánh giá kết quả sớm phẫu thuật cắt bán phần cực dưới và phục hồi lưu thông da dày - ruột theo Roux en $Y$ trong ung thu hang môn vi dạ dày tại bênh viện K từ 6/2019 đến 6/2021".

\section{II. ĐỐI TƯợNG VÀ PHƯƠNG PHÁP NGHIÊN CứU}

2.1. Thời gian và địa điểm. Bệnh nhân chẩn đoán ung thư hang môn vị từ 6/2019đến6/2021 được phẫu thuật cắt bán phân cực dưới và phục hôi lưu thông dạ dày-ruột theo Roux en Ytai bênh viên $K$.

\section{2. Đối tượng nghiên cứu}

2.2.1. Tiêu chuẩn lựa chọn. Bệnh nhân được chẩn đoán ung thư hang môn vị và phẫu thuật triệt căn theo tiêu chuẩn Hiệp hội Ung thư dạ dày Nhật Bản được phục hồi lưu thổng dạ dày ruôt theo Roux en Y.

Bệnh nhân được theo dõi sát, đánh giá biến chứng sớm sau mổ và tại thời điểm 6 tháng.

Bệnh nhân có hồ sơ bệnh án đầy đủ.

2.2.2. Tiêu chuẩn loại trừ. Vị trí khối u không thuộc vùng hang môn vị.
Phương pháp phục hồi lưu thông dạ dày ruột không phải Roux en Y.

Giai đoạn bệnh không thể phẫu thuật triệt căn.

Bệnh nhân có bệnh nền nặng (tim, phổi, gan, thân) hoặc nhóm phẫu thuât cấp cứu

Bệnh nhân hồ sơ không rõ ràng, mất liên lạc hoặc tử vong.

2.3. Phương pháp nghiên cứu. Phương pháp nghiên cứu mô tả, theo dõi dọc và không so sánh.

2.4. Các bước tiến hành

Bước 1: Chọn bệnh nhân theo tiêu chuẩn lựa chọn

Bước 2: Thu thập thông tin theo mẫu bệnh án nghiên cứu

-Ghi nhận đặc điểm lâm sàng, cận lâm sàng trước mổ

-Đánh giá biến chứng sớm sau mổ

-Đánh giá tại thời điểm 6 tháng sau mổ: biến chứng, chất lượng cuộc sống

\section{KẾT QUẢ NGHIÊN CỨU}

3.1. Đăc điểm đối tượng nghiên cứu. Tuổi mắc bệnh trung bình trong nghiên cứu là $57,55 \pm$ 11,12 tuổi, cao tuổi nhất là 85 , thấp nhất là 29 tuổi. Bệnh nhân trong độ tuổi 40-60 chiếm tỷ lệ cao nhất $(63,64 \%)$.

Tỷ lệ nam/nữ= 2,06/1 (chiếm lần lượt $67,27 \%$ và $32,73 \%$ ).

3.2. Thời gian nằm viên. Thời gian nằm viện trung bình là $8,65 \pm 2,30$ ngày, chủ yếu từ 7-9 ngày $(78,18 \%)$.

Bảng 3.1. Liên quan thời gian nằm viện và phương pháp phẫu thuật.

\begin{tabular}{|c|c|c|c|}
\hline $\begin{array}{c}\text { PP phâu } \\
\text { thuật }\end{array}$ & $\mathbf{N}$ & $\begin{array}{c}\text { Thời gian } \\
\text { TB } \pm \text { SD }\end{array}$ & $\mathbf{p}$ \\
\hline $\begin{array}{c}\text { Phấu thuật } \\
\text { nội soi }\end{array}$ & 11 & $7,36 \pm 1,21$ & $\begin{array}{c}0,004 \\
\text { (t-test) }\end{array}$ \\
\hline Mố mở & 44 & $8,98 \pm 2,41$ & \\
\hline Tống & $\mathbf{5 5}$ & & \\
\hline
\end{tabular}

Nhânn xét: Thời gian nằm viện nhóm phẫu thuật nội soi ngắn hơn nhóm mổ mở với sự khác biệt có ý nghĩa thống kê $(p=0,004)$.

\subsection{Biến chứng sớm sau mổ}

Bảng 3.2. Tỷ lể biến chứng sớm sau mổ

\begin{tabular}{|c|c|c|}
\hline Biến chứng & $\mathbf{n}$ & $\mathbf{\%}$ \\
\hline Chảy máu & 0 & 0 \\
\hline Rò (miệng nối, mỏm tá) & 0 & 0 \\
\hline Nhiêm trùng vết mố & 3 & 5,45 \\
\hline Viêm phối, nhiêmm khuấn tiết niệu & 0 & 0 \\
\hline
\end{tabular}

Nhânn xét: Tỷ lệ biến chứng sau mổ gặp 3/55 bệnh nhân $(5,45 \%)$, tất cả đều là nhiễm trùng vết mổ.

\section{4. Đánh giá tại thời điểm 6 tháng sau mổ} Bảng 3.3. Một số biến chứng thường gặp 
sau 6 tháng phẫu thuật

\begin{tabular}{|c|c|c|}
\hline Biến chứng & $\mathbf{n}$ & $\mathbf{\%}$ \\
\hline Trào ngược & 7 & 12,73 \\
\hline Viêm miệng nối & 14 & 25,45 \\
\hline Hội chứng Dumping & 2 & 3,64 \\
\hline Hội chứng Roux & 0 & 0 \\
\hline
\end{tabular}

Nhận xét: Một số biến chứng gặp phải: viêm miệng nối $(25,45 \%)$, trào ngược $12,73 \%$, hội chứng Dumping (3,64\%). Không có bệnh nhân nào mắc hội chứng Roux.

Bảng 3.4. Cân nặng và Chât lượng cuộc sống sau phẫu thuật

\begin{tabular}{|c|c|c|}
\hline Đặc Điếm & $\mathbf{n}$ & $\mathbf{\%}$ \\
\hline Cân nặng: Tăng & 46 & 83,64 \\
\hline Ôn định & 7 & 12,73 \\
\hline Giảm & 2 & 3,63 \\
\hline Chỉ số Spitzer: 0-5 & 0 & 0 \\
\hline $5-7$ & 5 & 9,09 \\
\hline $8-10$ & 50 & 90.91 \\
\hline
\end{tabular}

Nhận xét: Đa số bệnh nhân phục hồi cân nặng tốt sau mổ $(83,64 \%)$ và đạt chất lượng cuộc sống theo thang điểm Spitzer cao (8-10 điểm) chiếm tỷ lệ 90,91\%.

\section{BÀN LUÂN}

Tuổi trung bình của bệnh nhân trong nghiên cứu là $57,55 \pm 11,12$. Tỷ lệ nam/nữ $=2,06 / 1$. Kết quả này tương tự với các tác giả Nguyễn Văn Lượng, Chang In Choi ${ }^{3}, 4$.

Thời gian nằm viện trung bình là $8,65 \pm 2,30$ ngày. So sánh với nghiên cứu của các tác giả trong và ngoài nước, kết quả trong nghiên cứu của chúng tôi là tương đương 2,3, 4, 5. Khi phân tích liên quan thời gian nằm viện và phương pháp phẫu thuật chúng tôi nhận thấy, nhóm bệnh nhân được phẫu thuật nội soi có thời gian nằm viện trung bình $(7,36 \pm 1,21$ ngày) ngắn hơn nhóm mổ mở ( $8,98 \pm 2,41$ ngày), với sự khác biệt có ý nghĩa thống kê (với $\mathrm{p}=0.004$ ). Tỷ lệ biển chứng sớm sau mổ là $5,45 \%$. Kết quả này tương tự với các nghiên cứu của Nguyễn Văn Lượng $(4,8 \%)$, Chang In Choi và cộng sự $(2,5 \%)^{3,4}$.

Tỷ lệ viêm miệng nối sau mổ gặp $25,45 \%$ là cao hơn ở nhóm Roux en Y củacác nghiên cứu Đặng Vinhh Dũng, Nguyễn Văn Lượng, Jimmy Bok-Yan So17,2\%, 18,9\%, 16,05\% 2,3,6. Hội chứng Dumping gặp 3,64\%. Kết quả này tương đồng với nghiên cứu của Đặng Vĩnh Dũng $(5.2 \%)$, Long Hai Cui $(3.2 \%)$ và thấp hơn so với y văn kinh điển trước đây. Tỷ lệ trào ngược là $12,73 \%$. Không có trường hợp nào biểu hiện của hội chứng Roux. Tỷ lệ trào ngược và hội chứng Roux ở nhóm Roux en $Y$ lấn lượt trong các nghiên cứu Đặng Vĩnh Dũnglà $5,2 \%$ và $17,2 \%$ (quai Roux $50 \mathrm{~cm})$, Nguyễn Văn Lượnglà $13,2 \%$ và $7,5 \%$ (quai Roux $40-45 \mathrm{~cm}$ ), Chang In Choi là $30 \%$ và $0 \%$ (quai Roux $35 \mathrm{~cm}$ ), Jimmy Bok-Yan So là $2,47 \%$ và $13,58 \%$ (quai Roux $40 \mathrm{~cm}$ ) và của Long Hai Cui với trào ngược là 17,2\%2, 3,4,5,6. Khi so sánh các kết quả trên chúng tôi thấy rằng tỷ lệ gặp biến chứng trào ngược và hội chứng Roux giữa các nghiên cứu là không giống nhau. Sự khác biệt này có thể là do chiều dài quai Roux được mỗi tác giả lựa chọn trong kỹ thuật phục hồi lưu thông dạ dày-ruột ở các nghiên cứu là khác nhau, với quai Roux càng dài, tỷ lệ gặp trào ngược thấp hơn đồng thời tỷ lệ mắc hội chứng Roux sẽ cao hơn. Kết quả này phù hợp với tổng kết $Y$ văn thế giới của Gustavson, chiều dài trung bình của quai Roux ở những bệnh nhân có hội chứng Roux sau mổ là $41-50 \mathrm{~cm}$, so với $38-40 \mathrm{~cm}$ ở những bệnh nhân không có hội chứng ứ đọng Roux ${ }^{7}$.

Đa số bệnh nhân phục hồi cân nặng tốt sau mổ (83,64\%). Mặc dùtrào ngược gặp 12,73\% nhưng chủ yếu biểu hiện nhẹ, ít ảnh hưởngđến ăn uống của bệnh nhân. Kết quả này tương tự với nghiên cứu Đặng Vĩnh Dũng (92,3\%), Long Hai Cui $(90,3 \%)^{2,5}$. Chấtl ượng cuộc sống sau mổ theo thang điểm Spitzer cao (8-10 điểm) chiếm $90,91 \%$. Chỉ số Spitzer càng cao thì chất lượng cuộc sống càng cải thiện. Kết quả này cũng tương đồng với các nghiên cứu của tác giả Đặng Vĩnh Dũng $(89,6 \%)$, Nguyễn Văn Lượng $(90,2 \%)$ và các nghiên cứu nước ngoài khác như Long Hai Cui $(90,3 \%)^{2,3,5}$.

\section{KẾT LUÂ̂N}

Phục hồi lưu thông dạ dày - ruột theo Roux en Y sau phẫu thuật cắt bán phân cực dưới da dày mang lại nhiều lợi ích sau mổ cho bệnh nhân, đặc biệt nhóm được phẫu thuật nội soi với thời gian nằm viện ngắn, tỷ lệ biến chứng sớm, biến chứng tại thời điểm 6 tháng sau mổ thấp và chất lượng cuộc sống tốt.

\section{TÀI LIẸU THAM KHẢO}

1. Sung H, Ferlay J, Siegel RL, et al. Global Cancer Statistics 2020: GLOBOCAN Estimates of Incidence and Mortality Worldwide for 36 Cancers in 185 Countries. CA: A Cancer Journal for Clinicians. 2021;71(3):209-249. doi:10.3322/ caac.21660.

2. Đăng Vĩnh Dũng. Nghiên cứu hiệu quả của phương pháp phục hồi lưu thông dạ dày - ruôt theo Roux en $Y$ \& Billroth II trong phẫu thuât cắt đoạn dạ dày ung thư. Luận án Tiến sỹ y học. Thư viện Quiốc Gia. 2011; 3; 6-15.

3. Nguyển Văn Lượng. Nghiên cứu ứng dụng miệng nối Roux-en-y cải tiến sau cắt đoạn dạ dày cực dưới để điêu trị loét da dày - tá tràng và ung thư dạ dày. Luận án Tiến sỹ y học. Thư viện Quốc 
Gia. 2007; 4: 15-24.

4. In Choi C, Baek DH, Lee SH, et al. Comparison Between Billroth-II with Braun and Roux-en-Y Reconstruction After Laparoscopic Distal Gastrectomy. J Gastrointest Surg. 2016;20(6): 1083-1090. doi:10.1007/s11605-016-3138-7.

5. Cui L-H, Son S-Y, Shin H-J, et al. Billroth II with Braun Enteroenterostomy Is a Good Alternative Reconstruction to Roux-en-Y Gastrojejunostomy in Laparoscopic Distal Gastrectomy. Gastroenterol Res Pract.
2017;27(7):1803851. doi:10.1155/2017/1803851

6. So JB-Y, Rao J, Wong AS-Y, et al. RouX-en-Y or Billroth II Reconstruction After Radical Distal Gastrectomy for Gastric Cancer: A Multicenter Randomized Controlled Trial. Ann Surg. 2018;267(2):236-242. doi:10.1097/SLA.0000000000002229.

7. Gustavsson S, Ilstrup DM, Morrison P, Kelly KA. Roux-Y stasis syndrome after gastrectomy. Am J Surg. 1988;155(3):490-494. doi:10.1016/ s0002-9610(88)80120-x.

\section{ĐÁNH GIÁ KẾT QUẢ PHẪU THUÂT NộI SOI ĐƯờNG NÁCH VÚ TRONG ĐIỀU TRI U TUYẾN GIÁP LÀNH TÍNH TẠI BỆNH VIỆN ĐẠI HỌC Y HÀ NộI}

\section{TÓM TẮT}

Mục tiêu: Đánh giá kết quả phẫu thuật nội soi đường nách vú trong điều tri u tuyến giáp lành tính tai Bệnh viện Đại học Y Hà Nội. Đối tượng và phương pháp: Nghiển cứu mô tả hồi cứu - tiến cứu trên 33 bệnh nhân chẩn đoán u tuyến giáp lành tính được phẫu thuât nội soi tai Bênh viên Đai hoc Y Hà Nôi từ 06/2020 đến 06/2021. Kết quả: Trung bình là 33,8 9,8 tuổi, $100 \%$ nữ giới; tỷ lể 1 u trên lâm sàng $84,8 \%$, $u$ thùy phải $59,0 \%$, kích thước u trung bình $25,4 \pm 12,3 \mathrm{~mm}$. Trên siêu âm, u TIRADS 3 chiếm $66,7 \%$. Giải phẫu bệnh sau mổ bướu giáp keo chiếm $72,7 \%$. Cắt thuỳ tuyến giáp ở $97 \%$ trường hợp. Thời gian mổ trung bình $45 \pm 7$ phút; thời gian hẩu phẫu $5 \pm 0,9$ ngày. Nói khàn tạm thời chiếm $3 \%$; tê bì, giảm cảm giác da chiếm $12,1 \%$. 94\% phấu thuật được xếp loại tốt, $97 \%$ bênh nhân đánh giá hài lòng về kết quả phẫu thuật. Kết luận: Phẫu thuật nội soi đường nách vú trong điều trị u tuyến giáp lành tính tương đối an toàn, tỷ lệ tai biến, biến chứng thấp và đạt thẩm mỹ cao.

Từ khóa: U giáp trạng, phẫu thuật nội soi.

\section{SUMMARY}

\section{RESULTS OF ENDOSCOPIC THYROIDECTOMY} VIA UNILATERAL AXILLO-BREAST APPROACH IN TREATMENT OF BENIGN THYROID NODULE AT HANOI MEDICAL UNIVERSITY HOSPITAL

Objective: Evaluate the early results of endoscopic thyroidectomy via unilateral axillo-breast approach (UABA) in the treatment of benign thyroid tumor at Hanoi Medical University Hospital. Subjects and Methods: Descriptive retrospective studies 33 patients with benign thyroid tumors were treated by UABA at Hanoi Medical University Hospital from $6 / 2020$ to 06/2021. Results: Mean of age was $38.2 \pm 9.8$ years. All patients were female. The solitary

*Bênh viên Đai hơc Y Hà Nôi

Chịu trách nhiệm chính: Nguyễn Xuân Hậu

Email: nguyenxuanhau@hmu.edu.vn

Ngày nhận bài: 18.6.2021

Ngày phản biên khoa hoc: 16.8.2021

Ngày duyệt bài: 23.8.2021

\section{Nguyễn Xuân Hậu*, Nguyễn Xuân Hiền*}

tumor occults $93.3 \%$, the thyroid tumors in the right lobe were $59,0 \%$, the average tumor size was $25.4 \pm 12.3 \mathrm{~mm}$. The tumors classified into TIRADS 3 by ultrasound was $66,7 \%$. Most common pathology was colloid goitre accounting for $72,7 \%$. Lobectomy was applied in $97 \%$ cases. The mean operating time was $45 \pm 7$ minutes, the mean hospitalization was $5 \pm 0.9$ days. The hoarseness was presented in 1 patient $(3 \%)$. A patient developed numbness in the anterior cervical region which occults $3 \%$. $94 \%$ cases were calssified into good group and $97 \%$ patients were satisfied with cosmetic outcomes of UABA. Conclusions: Endoscopic thyroidectomy via unilateral axillo-breast approach was safe, and achived good cosmetic outcomes.

Key words: Thyroid nodule, endoscopy thyroidectomy, UABA.

\section{I. ĐĂT VẤN ĐỀ}

U giáp trạng là bệnh lý phổ biến nhất của tuyến nội tiết. Theo tổ chức y tế thế giới, tỷ lệ mắc u giáp trạng là $12 \%$. Nữ giới có tỷ lệ mắc bênh cao hơn nam giới, tỷ lệ nữ/ nam là 4/1. Chẩn đoán dựa vào lâm sàng kết hợp với siêu âm vùng cổ và chọc hút tế bào bằng kim nhỏ khối u.

Phẫu thuật là phương pháp quan trọng nhất điều trị khối u giáp trạng. Hiện nay có hai phương pháp phẫu thuật là mổ mở và mổ nội soi. Trong đó, phẫu thuật nội soi ngày càng được áp dung rông rãi.

Tại Việt Nam, nhiều phương pháp phẫu thuật nội soi đã được áp dụng như phẫu thuật nội soi đường miêng, phâu thuât nôi soi đường nách vú. Phẫu thuật nội soi đường nách - vú với những ưu điểm riêng do đó ngày nay vẫn được áp dụng trong điêu trị bệnh lý u tuyến giáp. Chúng tôi tiến hành nghiên cứu này nhằm đánh giá kết quả phẫu thuật nội soi đường nách vú trong điều trị u tuyến giáp lành tính tại Bệnh viện Đại học Y Hà Nội. 